Original Research

\title{
Responsive Feeding-Play (Resfeed-Play) Intervention on Children Aged 6-24 Months with Malnutrition
}

\section{Dwi Cahya Rahmadiyah, Agus Setiawan and Poppy Fitriyani}

Department of Community Health Nursing, Faculty of Nursing, Universitas Indonesia, Depok, Indonesia

\begin{abstract}
Introduction: Toddlers are at risk to health problems, one of which is malnutrition. One of the important determinants to toddlers' growth is nutrition. Giving solid foods to toddlers can be done by active/responsive feeding combined with the method that best suits the stage of playing toddlers. This paper aimed to provide an overview of the intervention of Resfeed-Play as a form of community nursing intervention on 32 children aged 6-24 months with malnutrition. Implementation of the intervention Resfeed-Play was performed in families and in society in nutrition support activities.
\end{abstract}

Methods: The method was quasi-experimental with one group pre-post-test design. The inclusion sample criterion was family with toddlers who suffered from malnutrition.

Results: The results of evaluation of Resfeed-Play shows an increase in knowledge (24.2\%), attitude and skills by $30.3 \%$ and $42.4 \%$, respectively. After intervention of six months, the mean weight gain for toddler was $0.95 \mathrm{Kg}$. Based on paired sample ttest, the weight gain is significant with a $\mathrm{P}$ value of $0.001(\mathrm{P}<0.05)$. Resfeed-Play intervention can increase body weight in toddlers and can address the problems of malnutrition in children under five.

Conclusion: Based on the results of this study, Resfeed-Play intervention is recommended to increase community empowerment through positive activities such as post-activity nutrition in order to prevent and mitigate the problem of malnutrition in toddlers.

\section{ARTICLE HISTORY}

Received: June 10, 2017

Accepted: May 2, 2018

\section{KEYWORDS}

Resfeed-Play; community nursing intervention; children aged 6-24 months; complementary feeding; growth

\section{CONTACT}

Dwi Cahya Rahmadiyah \.wicahyar@gmail.com $\equiv$ Department of Community Health Nursing, Faculty of Nursing, Universitas Indonesia

Cite this as: Rahmadiyah, D., Setiawan, A., \& Fitriyani, P. (2018). Responsive Feeding-Play (Resfeed-Play) Intervention on Children Aged 6-24 Months with Malnutrition. Jurnal Ners, 13(1), 24-30. doi:http://dx.doi.org/10.20473/jn.v13i1.4610

\section{INTRODUCTION}

One of the objectives of the Sustainable Development Goals (SDGs) by 2030 is to end all forms of malnutrition, including achieving internationally agreed targets on stunting and wasting in under-five children and meeting the nutritional needs of young women, pregnant women and breastfeeding mothers, and parents (Nations, 2015). Based on the MDG report by The United Nations (2015), the prevalence of under-five children with malnutrition continues to decline slowly for all regions to achieve the target. According to the global projection, the proportion of under-five children who were underweight between 1990 and 2015 has achieved the MDG's targets. However, more than 90 million children under five years old, or one in seven children worldwide, are still suffering from malnutrition (United Nations, 2015).
The prevalence of national under-five children's undernutrition was $13.9 \%$ in 2014 and $18.8 \%$ in 2015 . Based on the assessment of nutritional status of children under five years old (weight per age), among 69 samples of under-five children who were randomly assigned, $44.9 \%$ of children under five had good nutrition, $44.9 \%$ had undernutrition and $10.1 \%$ of children were severely malnourished. Signs and symptoms of undernutrition in the majority of children were in the yellow / red line (52.2\%). Based on survey results related to the health behavior domain, it was found that the level of family knowledge about undernutrition was $39.4 \%$ unfavorable, $42.4 \%$ of under-five children had poor attitude and $54.5 \%$ of families had poor skills (Rahmadiyah, 2015).

Undernutrition problems will have an impact on delayed child growth. Undernutrition can cause children to have a greater risk of infectious diseases, 
increasing frequency of disease and contributing to long-term healing. Undernutrition in the first 1,000 days of life is also associated with cognitive abilities and reduction in school and work performance (WHO, 2015). Various impacts of under-five children's undernutrition can cause them to be at risk of cognitive and physical disturbance.

The malnutrition problem among toddlers needs a comprehensive intervention including promotive, preventive and rehabilitative action as well as three levels of intervention, primary, secondary and tertiary. As a community nurse, the prevention of malnutrition has become one of the nurses' roles.

Strategies of intervention which can be used in community nursing practice for toddler groups with malnutrition include group discussion, partnership, community empowerment and other nursing complementary therapies (Pender, 2002; Stanhope and Lancaster, 2016). Based on those problems, this study used a concept model of community nursing, family nursing and health care management to overcome malnutrition among toddlers in the community. The concept model of community nursing care used community as partner (Ervin, 2002), while the model of family nursing care used family-centered nursing (Friedman, Bowden and Jones, 2003).

Based on the result of family assessment with toddlers in Srengseng Sawah Village in October 2016, randomized sample was used and showed that $44.9 \%$ toddlers are in good nutrition while $44.9 \%$ toddlers suffered from malnutrition and 10.1\% toddlers suffered from severe malnutrition. The signs and symptoms of malnutrition among toddlers is shown in yellow or red in the growth and development chart (52.2\%). Based on the survey related to health behavior, this has shown a poor level of family knowledge about malnutrition (42\%) and $44.9 \%$ of the families did not show good health behavior. However, $60.9 \%$ of the toddlers were found with good behavior (Rahmadiyah, 2015).

Within the context of feeding, responsiveness includes offering physical assistance appropriate to the age of the child and with consideration to the child's hunger and satiety cues, feeding patiently, offering verbal encouragement to eat, trying different foods and encouraging the child if he refuse to eat, avoiding distractions during meals, and talking and making eye contact during feeding (Pan American Health Organization \& World Health Organization, 2003). Studies of caregiver styles of feeding in resource-poor settings suggest that responsive feeding behaviors are associated with higher child acceptance of food (Ha et al., 2002; Moore et al., 2006; Dearden et al., 2009; Bentley et al., 2011). Caregivers have also been shown to feed children more actively during certain types of meals (Engle and Zeitlin, 1996).

Young children raised by caregivers who eat healthy foods, such as a diet rich in fruits and vegetables, are more likely to choose and prefer fruits and vegetables (Skinner et al., 2002). In contrast, children of caregivers who exhibit unhealthy dietary behaviors (i.e. diets high in refined carbohydrates and saturated fats) are likely to develop unhealthy diets themselves (Papas et al., 2009). When caregivers engage in responsive interactions with their children, they are likely to maintain the child's feeding in the short term, the clarity of expressed signals of hunger and satiety, and, ultimately, responsibility for recognizing and acting on such signals. A recent survey of health and nutritional personnel from six countries endorsed parenting practices characterized by structure, nondirective control and responsiveness as being most effective in promoting fruit and vegetable consumption among toddlers (O'Connor, 2010). The literature shows that active-responsive feeding is the basis for developing good eating behaviors and optimizing skills to organize themselves as well as self-control about food intake. Therefore, practicing active-responsive feeding is associated with ideal growth, optimal nutrition and long-term weight regulation (Harbron, Booley and Najaar, 2013).

One of the innovative interventions in this study to improve the nutritional status of toddlers in Srengseng Sawah Village was increasing active and responsive feeding with Responsive feeding and play (Resfeed-Play) intervention. This intervention included active and responsive feeding combined with playing educational games for toddlers. Activeresponsive feeding can be done by the mother as a caregiver to avoid the problem of malnutrition. Feeding actively and responsively refers to a mutual relationship between toddler and mother characterized by the toddler whereby they can communicate about hungry and satisfied feelings through verbal and nonverbal cues, followed by an immediate response from their mother (Du Plessis, Kruger and Sweet, 2013). Responsiveness during feeding is defined as caregivers' prompt, contingent and developmentally and emotionally appropriate reactions to their children (Ainsworth et al., 1974; Black and Aboud, 2011). The aim of this research is to provide an overview of the implementation of Responsive Feeding and Play (Resfeed-Play) intervention in community care and nursing care in increasing weight in toddler aggregate.

\section{MATERIALS AND METHODS}

The study used quasi-experimental by one group pre-post-test design. The inclusion criterion for sample recruitment was family with toddlers who suffered from malnutrition. The sample selected in this study consisted of 32 mothers with children aged 6-24 months, the child was still breast-fed and follow up at the integrated healthcare service center (Posyandu) was also taken during the study period. This research was conducted in Srengseng Sawah Sub-district, Jagakarsa district, South Jakarta. Based on the nutritional status assessment of under-five children (weight per age), among 69 randomized toddler samples, $44.9 \%$ of toddlers had good 
nutrition, $44.9 \%$ had undernutrition and $10.1 \%$ had severe undernutrition. Signs and symptoms of underweight nutrition in the majority of children were in the yellow/red area in monitoring card (52.2\%). Data collecting instruments consisted of questionnaires to measure knowledge, behavior and skills related to malnutrition and a weighing instrument to measure body weight of children under the age of two years old. The validity test on the questionnaires concerning knowledge, behavior and skills produced a value of $0.372-0.793$ while the reliability test produced a value of 0.852 . The weighing instrument to measure body weight of children under the age of two years old was hanging scales that had been calibrated. This study passed the ethical test standards for research as outlined by Faculty of Nursing Universitas Indonesia before data collection. This study used paired sample t-test for data analysis.

This research conducted responsive feeding combined with play method as the intervention. Participants were given education about responsive feeding and play methods. The variables to be measured are mother's knowledge, attitude and behavior towards responsive feeding before and after intervention. Implementation was conducted for three time periods within three months. One period was done daily for two weeks in the form of a nutrition support. After a period of implementation, the intervention was evaluated by measuring weight gain of toddlers and mother's behavior in the provision of complementary feeding (MPASI) for toddlers. Activities undertaken in the nutrition support included the mothers processing the ingredients to be food for the toddler, then, after processing the ingredients, the mothers fed their children while playing. During the nutrition support, the participants were accompanied by two facilitators in processing food ingredients into MPASI. The facilitators were health volunteers who had been trained in responsive feeding and play methods by the researcher. The facilitators played a role in assisting the toddler's mother in the processing of food ingredients, providing positive reinforcement and measuring the weight of toddlers every day during the nutrition support. In addition, the role of the facilitator was also to monitor the behavior of the infant's mother in the practice of giving complementary feeding (MPASI) through incidental home visits.

The implementation of the Resfeed-Play consisted of environmental requirements and several steps. The environmental requirements must be considered by parents in terms of the environment while active-responsive feeding is given and things that need to be considered before inviting the toddlers to play. Before parents give an active-responsive feeding, there are things that must be considered, such as the eating environment. Some environmental requirements that can be created include a pleasant eating environment, children sitting relaxed and comfortable, face contact with other family members, minimized distractions during meals, establishing a routine, and following the schedule which should be at the same time and place (Harbron, Booley and Najaar, 2013).

Some guidelines mother should pay attention to in assisting toddlers during their play include making sure toys are safe and appropriate to their age; providing toys to stimulate all the children's senses; putting the baby in various position throughout the day (e.g., stomach, side, back [if the baby can turn from supine to prone position; encouraging the use of hands and feet in play; offering some new experiences every day, encouraging to bang the toys together; giving praise more often; and reading stories for children (before nap time and bedtime) (Dixon and Stein, 2006 cited in Potts and Mandleco, 2011; Bright Futures, 2009). Mothers as a caregiver can facilitate children's signals and reciprocity through proactive preparation. Some guidelines to initiate play include the provision of age-appropriate play materials, some new and some familiar, and keeping the child in place, engaged and at liberty to act on the materials and emit signals. This proactive preparation provides a structure so the child knows what to do and can explore new options and the caregiver can provide support that expands on the child's repertoire. Guidelines for feeding and proactive preparation include establishing routines around mealtimes, such as eating in the same place and at the same time; ensuring that children are seated in a supportive and comfortable position; and exposing them to appropriate mealtime behavior, such as making healthy choices for the entire family (Black and Hurley, 2010).

\section{RESULTS}

Based on the family characteristics, the study revealed the average age of the mother is 29 years (95\% CI: 26.93-31.07) with standard deviation of 5.742 . The youngest age 19 years and the oldest age 44 years.

Less than half of the families surveyed, or $40.6 \%$ of them, belong to low-income families (i.e. their income is below the UMR (regional minimum wage) or less than 2.700.000 rupiah); more than half of mothers, 78.1\%, have level senior high school education.

Based on Table 3, the result of the paired sample t-test showed the mean weight of toddlers before the intervention was $8.0594 \mathrm{~kg}$ with standard deviation of 1,814 . After intervention of six months, the mean weight gained was $9.009 \mathrm{~kg}$ with standard deviation of $0.95 \mathrm{~kg}$. After further analysis, there was a significant weight gain with $\mathrm{p}$-value $0.001(\mathrm{p}<0.05)$.

Based on Figure 1, it shows that there was an increase in knowledge, behavior and skill before and after a nursing intervention. After intervention of six months, there was an increase of $24.2 \%$ in knowledge, $30.3 \%$ in behavior and $42.2 \%$ in skills. 
Table 1. Distribution of Mother's Age in the Group of Malnutrition Toddlers ( $\mathrm{n}=32)$

\begin{tabular}{ccccc}
\hline Variable & Mean & SD & Min-Max & 95\% CI \\
\hline Mother & 29 & 5.742 & $19-44$ & $26.93-$ \\
age & & & & 31.07 \\
\hline
\end{tabular}

Table 2. Distribution of Family Characteristics in the Group of Malnutrition Toddlers $(n=32)$

\begin{tabular}{ccc}
\hline Family & Amount & Percentage \\
Characteristics & & \\
\hline Family income & & 59.4 \\
High $(\geq$ UMR: $\geq$ & 19 & 40.6 \\
$2.700 .000)$ & & \\
Low $(<$ UMR: $\leq$ & 13 & 15.6 \\
$2.700 .000)$ & & 78.1 \\
Mother's education & & 6.3 \\
Junior high school & 5 & \\
Senior high school & 25 & \\
College & 2 & \\
\hline
\end{tabular}

Table 3. Distribution of Weight in the Group of Malnutrition Toddlers ( $\mathrm{n}=32$ )

\begin{tabular}{lcccc}
\hline & Mean & SD & $\begin{array}{c}\text { Mean } \\
\text { Range }\end{array}$ & P-value \\
\hline $\begin{array}{l}\text { Weight } \\
\text { Before } \\
\text { Weight }\end{array}$ & 8.0594 & 1.814 & 0.95 & 0.001 \\
After & 9.0094 & 1.848 & & \\
\hline
\end{tabular}

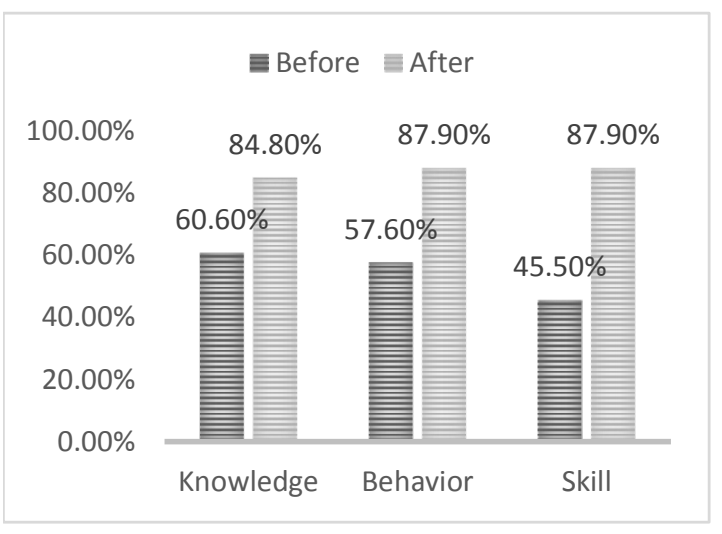

Figure 1. Frequency Distribution in a Group of Mothers and Toddlers based on Knowledge, Behavior and Skills Related to Malnutrition Before and After Intervention $(n=32)$

\section{DISCUSSION}

The human resources organization in Posyandu has formed a support group to provide healthcare service for children. These support groups consist of a health representative, known as a health volunteer, for nutrition support. These support groups served as facilitators in the nutrition support activities. The facilitators' roles in this activity were to facilitate the participant in the nutrition support activities, provide motivation to the participants in the intervention of active-responsive feeding during playing educational games with toddlers, giving advice to the participant and making regular home visits.
Both support group and self-help group had roles and functions that would complete each other in a nutrition support activity. Each group had the power to overcome the nutritional problems in the community. The role of support groups in the nutrition support activity included giving support, motivation, and encouragement to participants' nutrition support, while the role of self-help groups was in giving strength and shared experiences among participants. Both groups were part of the organization formed as nutrition support. This is consistent with the theory of organization which include working in an organizational structure, understanding and using the power and authority appropriately (Marquis and Huston, 2012). This support group was given guidance by the health professionals to maintain this nutritional program for toddlers. Support groups who were given a guidance by health professionals saw an increase of $15 \%$ in knowledge.

The implementation strategy was done by the community as a partner model. The strategy is used in this implementation involves health education, group process, partnership and empowerment (Anderson and McFarlan, 2011). Health education strategies performed in the community include health education about malnutrition, balanced nutrition, and active-responsive feeding to the toddlers in the comm

unity. This activity included primary prevention. This is in accordance with Stanhope and Lancaster, (2016) who declared that primary prevention is a prevention before illness and focused on healthy population, including general health activities and specific protection against disease.

The purpose of health education, according to Yazachew and Alem (2004), is to motivate an individual to adopt a health behavior through health promotion by providing proper knowledge and developing a positive attitude. It also helps individuals to make decisions about their health and gain confidence and skill to take the decisions (Yazachew and Alem, 2004). Based on that explanation, the purposes of education are divided into short-term goals to achieve knowledge change while medium-term goals are increase in knowledge, behavior and skill that will be changed towards healthy behavior. The long-term goals are to run health behavior in their daily life. This is in accordance with the results before and after health education which showed an increase in knowledge, attitude and skills by $24.2 \%, 30.3 \%$ and $42.4 \%$, respectively.

The other implementation strategy was the group process, not only the self-help group formed by mothers who have malnutrition toddlers, but also the implementation of nutrition support activities. The groups consisted of the families who have toddlers with malnutrition and undertake activities in the nutrition support. The activities included cooking together, performing active-responsive feeding and shared experiences about how to 
provide food for toddlers. The implementation of this strategy is considered as secondary prevention in the nursing community to overcome health problems. The secondary prevention emphasis is on early diagnosis and implementation to prevent the disease process (Stanhope and Lancaster, 2016). The nutrition support activities aimed to increase knowledge and awareness among parents with malnutrition toddlers, improve the autonomy to take preventive actions against malnutrition and any complication, and improve parents' ability to overcome malnutrition independently by providing and processing food properly as a prevention of malnutrition among children living in two areas in Srengseng Sawah Village.

The result showed that a self-help group for parents who have malnutrition toddlers was formed in two areas and which consisted of 19 and 13 participants $(n=32)$. In addition, $80 \%$ of participants of nutrition support gained their weight between 1-4ozs during the first two weeks. All the participants also demonstrated how to process wellnourished food, performed active-responsive feeding every day for two weeks in the nutrition support, and developed appropriate responses. This result proposes that the short-term benefits of responsive feeding are expected to be children's increasing attention to internal signals of hunger and satiety and to eating in a competent and responsible manner. The long-term benefits of responsive parenting are enhanced psychosocial, cognitive and language competence, and the long-term benefits of responsive feeding are likely to include healthy nutrition and growth (Black and Aboud, 2011). Research is needed to examine the short and longterm impact of responsive feeding on children's growth and development.

The home visit was performed by health volunteers to monitor food processing with balanced nutrition and active-responsive feeding every day at home. In addition, these nutrition support activities also have an impact on the behavior of the mother, such as cooking a meal with balanced nutrition, feeding actively and responsively, and washing hands at home. Those were all evaluated through unplanned home visits by the health volunteer. The results are in accordance with one of the evaluation criteria mentioned by Ervin (2002) in that evaluation focused on community nursing care is to see the improvement of health status as an impact after the program was performed and to observe the changes over the course of six months to a year.

The implementation of a planned empowerment strategy includes the formation and training of a support group. This training is expected to support the malnutrition prevention activity in two areas. These support groups consist of health volunteers and public figures in the community who are empowered in order to address the problem of malnutrition experienced by the toddlers. This group serves as a facilitator for the self-help group.
Every toddler in the assisted family has performed Resfeed-Play intervention that has been taught to the previous family. The active responsive feeding provided strategies which can be done by parents included actively engaging in eye contact and talking with the children during mealtime, talking about expectations, responding to hungry and satisfied feelings, feeding the baby directly, or helping children to eat by themselves (Harbron, Booley and Najaar, 2013). This feeding was practiced in line with the theory that the average mothers from 32 toddlers were actively involved and talked to their children during mealtime. The average mothers from 32 toddlers were also making eye contact with the children during feeding. This process is in accordance with research that, within the context of feeding, responsiveness includes offering physical assistance appropriate to the age of the child and with respect to the child's hunger and satiety cues, feeding patiently, offering verbal encouragement to eat, trying different foods and methods of encouragement if the child refuses, keeping distractions to a minimum during meals, and talking and making eye contact during feeding (Pan American Health Organization \& World Health Organization 2003). Studies of caregiver styles of feeding in resource-poor settings suggest that responsive feeding behaviors are associated with higher child acceptance of food (Ha et al., 2002; Moore et al., 2006; Dearden et al., 2009; Bentley et al., 2011). Caregivers have also been shown to feed children more actively during certain types of meals (Engle and Zeitlin 1996).

The strength of this study is that intervention of Resfeed-Play was a procedure of feeding the toddler which was quite easy to do, both in the family and in the community in nutrition support activities. This intervention did require the mother's patience in its implementation. The essence of this intervention was to feed the toddler with affection and patience interspersed with educative games that could stimulate the development of toddlers.

Despite there was notable improvement in the knowledge, attitudes and skills of mothers as well as increase in the weight of the toddlers, some limitation was identified. This included the selection of the village, which was not randomized since the study was conducted as part of intervention in a residential program of a community nursing specialist program. Other limitations of this study were that not all mothers were patient when feeding toddlers and had time to cook their own food for toddlers. This was because the mothers of toddlers with undernutrition were mostly housewives whereby all household chores were handled by themselves, without any household assistants or other family member helping.

Another limitation was the limited number of health volunteers involved in nutrition support. Up to this time, the health volunteers of Posyandu (Integrated child health services) have also been health volunteers of nutrition support. Currently, the 
government has promoted health programs that require community empowerment. In these cases, health volunteers became the main representative of healthcare staff in the community to empower people in their area, which resulted in increasing their workload. This placed the workload on the health volunteers since they were also the health volunteers for Posyandu, larvae observation (Jumantik), tuberculosis, and also the contraception program. As a result of the multiple tasks and roles they did, it reduced their focus on implementing each program. Thus, the expected outcomes of each program, particularly the program of nutrition support, was not optimally done.

\section{CONCLUSION}

There was increased knowledge, behavior and skill of every support group members, mothers' group with malnutrition children, and families after performing Resfeed-Play intervention. Training programs for community representatives and implementation of nutrition support were effective activities that can be done to overcome malnutrition problems. Furthermore, increased family's independence in addressing malnutrition in children through Resfeed-Play intervention also increased children's weight after Resfeed-Play. In addition, it is expected that Public Health Centers (Puskesmas) can develop nutrition program activities of toddlers involving cadres of nutrition support with the implementation of responsive feeding to improve nutritional status in toddlers. Puskesmas can also provide ongoing guidance to nutrition support cadres and other support group members in conducting guidance, motivation and improving community spirit in overcoming malnutrition problem in toddlers.

\section{ACKNOWLEDGMENT}

We are grateful to the participants for their help and patience during this study. Also, we thank the Jagakarsa Community Health Center for their support and cooperation in this study.

\section{REFERENCES}

Anderson., A and McFarlane, J. (2011). Community as Partner: Theory and Practice in Nursing. 6th ed. Philadelphia: Lippincottt Willims \& Wilkins.

Ainsworth, M.D.S., Bell, S.M. and Stayton, D.J. (1974). Infant- mother attachment and social development: 'socialization' as a product of reciprocal responsiveness signals. In: Richards, M.P.M. (ed.), The Integration of a Child into a Social World. London: Cambridge University Press, pp 99-135.

Bentley, M.E., Wasser, H.M. and Creed-Kanashiro, H.M. (2011). Responsive feeding and child undernutrition in low- and middle-income countries. Journal of Nutrition 141, pp. 502-507.
Black, M.M. and Aboud, F.E. (2011). Responsive feeding is embedded in a theoretical framework of responsive parenting. Journal of Nutrition 141, pp. 490-494.

Black, MM and Hurley K. (2010). Infant nutrition. In: Bremmer, J.G. and Wachs, T (eds.), Handbook on infant development. 2nd vol. Applied and policy issues. New York: Wiley-Blackwell, pp. 33-61.

Dearden, K.A., Hilton, S., Bentley, M.E., Caulfield, L.E., Wilde, C., Ha, P.B. and Marsh, D. (2009). Caregiver verbal encouragement increases food acceptance among Vietnamese toddlers. Journal of Nutrition 139 (7), pp. 187-1392.

Dewey, K.G. and Adu-Afarwuah, S. (2008). Systematic review of the efficacy and effectiveness of complementary feeding interventions in developing countries. Maternal and Child Nutrition, 4(1, pp. 24-85.

Du Plessis, L.M., Kruger, H.S. and Sweet, L. (2013). Complementary feeding: a critical window of opportunity from six months onwards. South African Journal of Clinical Nutrition, 26(3), S129-S140.

Engle, P.L. and Zeitlin, M. (1996). Active feeding behavior compensates for low interest in food among young Nicaraguan children. Journal of Nutrition 126, pp. 1808-1816.

Ervin, N. E. (2002). Advanced Community Health Nursing Practice: Population-Focused Care. New Jersey: Prentice Hall.

Fein, S.B., Labiner-Wolfe, J., Scanlon. K.S. and Grummer-Strawn, L.M. (2008). Selected complementary feeding practices and their association with maternal education. Pediatrics, 122(2): pp. 91-97.

Friedman., M., Bowden., V.R. and Jones., E.G. (2003). Family Nursing: Research Theory \& Practice. 5th ed. New Jersey: Person Education Inc.

Ha, P.B., Bentley, M.E., Pachon, H., Sripaipan, T., Caulfield, L.E. and Marsh D.R. and Schroeder, D.G. (2002). Caregiver styles of feeding and child acceptance of food in rural Vietnam. Food and Nutrition Bulletin, 23(4), pp. 95-100.

Harbron, J., Booley, S. and Najaar, B. (2013). Responsive feeding: establishing healthy eating behaviour early on in life. South African Journal of Clinical Nutrition, 26(3), S141-149

Hockenberry, J and Wilson, D. (2008). Wong's Essentials of Pediatric Nursing. 8th ed. USA: Mosby.

Lesiapeto, M.S., Smuts, C.M., Hanekom, S.M., Du Plesis, J. and Faber, M. (2010). Risk factors of poor anthropometric status in children under five years of age living in rural districts of the Eastern Cape and KwaZulu- Natal Provinces, South Africa. South African Journal of Clinical Nutrition, 23(4), pp. 202-207.

Marquis, B.L., and Huston, C.J. (2012). Leadership Roles and Management Functions in Nursing; Theory and Application. USA: Lippincott Williams \& Wilkins. 
Moore, A.C., Akhter, S. and Aboud, F.E. (2006). Responsive complementary feeding in rural Bangladesh. Social Science and Medicine, 62, pp. 1917-1930.

O'Connor, T., Watson, K., Hughes, S., Beltran, A., Hingle, M., Baranowski, J., Campbell, K., Canal, D.J., Lizaur, A.B., Zacarías, I, González, D., Nicklas, T. and Baranowski, T. (2010). Health professionals' and dietetics practitioners' perceived effectiveness of fruit and vegetable parenting practices across six countries. Journal of the Academy of Nutrition and Dietetics,110 (7), pp. 1065-1071.

Papas, M.A., Hurley, K.M., Quigg, A.M., Oberlander, S.E. and Black, M.M. (2009). Low-income African American adolescent mothers and their toddlers exhibit similar dietary variety patterns. Journal of Nutrition Education and Behavior, 41(2), pp. 8791.

Pender, N.J. (2002). Health Promotion in Nursing Practice. USA: Simon \& Schuster.

Potts, N.L., and Mandleco, B.L. (2012). Pediatric Nursing Caring For Children and Their Families. 3rd ed. USA: Delmar, Cengage Learning.
Pan American Health Organization \& World Health Organization (2003) Guiding Principles for the Complementary Feeding of the Breastfed Child. PAHO: Washington, DC.

Rahmadiyah, D.C. Laporan Akhir Komunitas RW 07 Srengseng Sawah. (2015). Tidak dipublikasikan

Skinner, J.D., Carruth, B.R., Bounds, W., Ziegler, P. and Reidy, K. (2002). Do food-related experiences in the first two years of life predict dietary variety in school- aged children? Journal of Nutrition Education and Behavior, 34, pp. 310-315.

Stanhope, M. and Lancaster, J. (2016). Foundation of nursing in the community: Community-oriented practice. 8th ed. USA: Mosby

United Nations. (2015). The Millennium Development Goals Report.

United Nations (2015). Transforming our world: the 2030 agenda for sustainable development.

Yazachew, M. and Alem, Y. (2004). Introduction to health education. In collaboration with the Ethiopia Public Health Training Initiative. The Carter Center, the Ethiopia Ministry of Health, and the Ethiopia Ministry of Education. USAID Cooperative Agreement No. 663-A-00-00-035800 . 